\title{
Factors associated with cessation of exclusive breastfeeding before six months among mothers in the Miramichi region (Canada)
}

\author{
Louise Anin Atchibri ${ }^{1}$, Etienne Dako ${ }^{2}$, \\ ${ }^{1}$ Laboratory of Nutrition and Food Safety (LANUFS); Faculty of Sciences and Food Technologies. Nangui \\ Abrogoua University, Abidjan, Côte d'Ivoire \\ ${ }^{2}$ School of Food Science, of Nutrition and Family Studies; Faculty of Health Sciences and Community Services, \\ University of Moncton, Moncton, NB, Canada
}

\begin{abstract}
The study was designed to investigate the cessation factors associated with the exclusive breastfeeding in the Miramichi region. It was a descriptive cross-sectional and analytical study, which took place from 2011 to 2014. A total of 294 mothers and their 294 children aged from 0 to 42 months constituted the study population. The data collection concerning the breastfeeding in infant was done by questionnaire addressed to the parents. A multivariate statistical analysis was realized to identify the determinants of the exclusive breastfeeding cessation. The adjusted Odds Ratio (ORa) and their interval were calculated. The average age of mothers and the duration of breastfeeding were respectively $26.86 \pm 6.44$ years and $19.22 \pm 3.28$ months. In multivariate analysis, the early cessation of exclusive breastfeeding is associated with the maternal age (adjusted odds ratio $(\mathrm{ORa})=1.2)$, the level of education of the mother $(\mathrm{ORa})=1.6)$, the mode of feeding $(\mathrm{ORa})=1.9)$, and the duration of breastfeeding $(\mathrm{ORa})=2.2)$; which are predictors of childhood obesity in Miramichi. We have identified modifiable factors in order to improve the practice of exclusive breastfeeding in Miramichi Factors associated with cessation of exclusive breastfeeding before six months among mothers in the Miramichi region (Canada)
\end{abstract}

Keywords: Exclusive breastfeeding, duration, associated factors, six months, Miramichi

\section{INTRODUCTION}

The breastfeeding alone covers the nutritional needs of infants during the first 6 months of their life [1]. It is recognized as the optimal form of infant feeding. Indeed, breastfeeding also has beneficial effects on infant health as well as that of his mother $[2,3]$. The effect of exclusive breastfeeding on cognitive development have been demonstrated [4].The World Health Organization (WHO) recommends exclusive breastfeeding (without any other food or drink) until the age of 6 months, followed by partial breastfeeding until the age of 2 years [3]. In Canada, as in many countries, the promotion of breastfeeding is inscribed in public health programs [4]. Thus, during these recent years, the Agency of Health Canada, Health Canada, the Canadian Pediatric Society and the Dietitians of Canada, have recommended the exclusive breastfeeding for the first six months, after the birth of term infants and in good health, and the maintaining of the breastfeeding up to two years and more [5]. According to some international and national health organizations, such as the UNICEF, the World Health Organization (WHO) or the Canadian Pediatric Society, the benefits of breastfeeding are linked to its duration and to its exclusivity.These recommendations are more or less followed in Canada. In 2010, the exclusive breastfeeding at the exit of the maternity ranged between 70 and 84\% [6]. In New Brunswick, the breastfeeding rate is one of the lowest in Canada, despite the increase of 53\% in 2004 and 63\% in 2014, the province is still significantly behind the national level of about $84.5 \%$. In CANADA, strong social disparities persist, and there is very little statistical data in each province on the breast duration and its exclusivity. However, studies show that the socio demographic characteristics of women, the contact with health professionals and some hospital practices could have an effect on the exclusive breastfeeding. The objective of this study was to describe the maternal factors associated with the cessation of exclusive breastfeeding before six months in mothers of the Miramichi region. The specific objectives are the following: estimate the rate of mothers who stopped breastfeeding during the first six months of the child's life; identify the characteristics associated with the cessation of exclusive breastfeeding.

\section{MATERIAL AND METHODS}

\subsection{Type of study and Study Population}

It is a cross-sectional study, descriptive and analytical, conducted in the mother-child couples who attended the immunization services. The target population is composed of all breastfeeding mothers who have declared breastfeed their infant at the maternity (breast only, mixed or formula) and of those who have answered to all the questions on the explanatory variables. Children aged from 0 to 42 months and mothers or fathers of 
Miramichi region, in New Brunswick province in Canada.A questionnaire has been realized according to the recommendations of the Public Health Agency of Canada, Health Canada, the Canadian Pediatric Society and of the Dietitians of Canada, on the exclusive breastfeeding during the first six months, after the birth of term infants and in good health; and on recommendations of the maintaining of breastfeeding up to two years and more in the New-Brunswick. In addition to the questionnaires, informations were collected from the medical records of the mother, father and child. The dependent variable of the study is the duration of exclusive breastfeeding. The independent variables are the factors related to the mother, to the father and the infant. That is to say, maternal age, marital status, education level, occupation, monthly household income, consumption of tobacco, the method and duration of breastfeeding; in children, these variables are: sex, child's weight at birth, the feeding method adopted, dietary diversification age, and factors related to the environment.

\subsection{Statistical Analysis}

The data were recorded and analyzed. These have permitted to estimate the association between the targeted variables and the breastfeeding duration. The first step has permitted to identify the variables that must been included in the regression model. Finally, a logistic regression analysis permitted to identify the factors that must better explain the duration of breastfeeding. The multivariate analysis, by logistic regression, was performed with a significance level of $5 \%$.

\section{RESULTS AND DISCUSSION}

In total $31.6 \%$ of women breastfed exclusively, $35.1 \%$ with the mixed way and $33.3 \%$ with the artificial way between 0 and 6 months. In contrast between 6 and 12 months, the children were less exclusively breastfed and in mixed ways; the rate of exclusive breastfeeding decreased to $17,4 \%$ and that of the mixed feeding to $18,5 \%$. But, artificial feeding has increased to $64.1 \%$. The prevalence of breastfeeding decreases with time: it is no more than $17.7 \%$ at the end of the 12th month (Table 1). The figure 1 shows the breastfeeding prevalence during the first year for all eligible participants. The prevalence of breastfeeding fell from $69.7 \%$ at birth to $53.8 \%$ at 1 month. At 6 months, $17.4 \%$ of mothers still breastfeeding their children, and $18.5 \%$ with the mixed manner. At 1 year, $5.3 \%$ of infants were still breastfed, and $2.9 \%$ exclusively. In mothers who initiated breastfeeding $(\mathrm{N}=291)$, the median total duration of breastfeeding was 17 weeks, and that of the exclusive breastfeeding was 7 weeks. Among the variables in the regression model below, seven have permitted to explain the cessation of breastfeeding at six months: the age of the mother $(\mathrm{OR}=1.8: 95 \% \mathrm{CI}[1,59-2,85] \mathrm{p}=0.001)$, the marital status $(\mathrm{OR}=2.97: 95 \% \mathrm{CI}(0,93-3,15) \mathrm{p}=0.001)$, the level of education $(\mathrm{OR}=2,12: 95 \% \mathrm{CI}(1,95-$ $4,09) \mathrm{p}=0.001)$, the occupation $(\mathrm{OR}=1,74: 95 \% \mathrm{CI}(0,15-2,55) \mathrm{p}<0.001)$, the socioeconomic category $(\mathrm{OR}=$ 1,9: $95 \% \mathrm{CI}(0,90-2,85) \mathrm{p}<0.001)$, the smoking ( $\mathrm{OR}=3,9: 95 \% \mathrm{CI}(1,5-8,1) \mathrm{p}=0.001)$, Type of breastfeeding $(\mathrm{OR}=3,1: 95 \% \mathrm{CI}(0,15-0,55) \mathrm{p}<0.001)$, and Duration of breastfeeding $(\mathrm{OR}=2,1: 95 \% \mathrm{CI}(0,90-2,85) \mathrm{p}$ $<0.001$ ) (Table 1).This study aimed to estimate the rate of breastfeeding and to describe the maternal factors that are associated with the stopping of the breastfeeding before six months in the Miramichi region. Indeed, the results show that the total duration of the breastfeeding was 17 weeks in breast-fed infants. These results are due to the breastfeeding promotion actions initiated in Canada, in the Canada Health Framework [7]. However, the duration of breastfeeding is very far from the level of the recommendations required by the WHO (6 months exclusively). In the study, only $31.6 \%$ of infants were still breastfed exclusively for 6 months. These values are in bellow of the prevalence of the breastfeeding recorded by some provinces. Although the New Brunswick has adopted the Initiative "Friendly Baby" as a strategy to protect, promote and support breastfeeding, the initiation rate of breastfeeding is around $63.3 \%$.

For an effective policy of breastfeeding promotion, it is necessary to better understand the factors influencing the duration of the breastfeeding. Generally three types of approaches are used: the sociodemographic studies, the psychological studies of refusal or abandonment of the breastfeeding, and the studies exploring the representations of the mother to understand the reasons underlying the decision to breastfeed and the pursuit of this practice. In this study, we looked at the socio-demographic approach associated with the duration of the breastfeeding in the multivariate analyzes. The study by multivariate analysis found a number of factors now relatively well known to influence the duration of the breastfeeding, and which have been well analyzed in the studies of Taveras [8] and Scoot. [9].The results show that the exclusive breastfeeding followed during more than 6 months is significantly more common in women aged over 35 years (OR: 2.4 95\% CI(1.5, 4.0). This concept takes all its importance in the current context where the pregnancies are increasingly late especially among working women belonging to the middle and to the upper socio-professional categories. The exclusive breastfeeding rate is significantly higher for the older mothers than among the less old mothers. Indeed, the young mothers are 1.8 times more likely to stop the exclusive breastfeeding than older mothers. This predominance related to the age was also reported by another study [10]. The maternal age remains an important criterion and is associated with the choice of breastfeeding as well as its duration. We note that the breastfeeding digits at the exit of the maternity are not a meaningful indicator because of the early stops of the breastfeeding. 
In addition, it does not permit to distinguish neither the characteristics of mothers who abandon the breastfeeding prematurely after leaving the maternity and those who continue this practice, nor the factors explaining an abandon, or a practice more or less longer of the breastfeeding. The work has also showed a positive correlation between the marital status of the mother and the pursuit of the breastfeeding $(\mathrm{OR}=2.2 \mathrm{p}$ $<0.001$ ). Some studies have shown that married mothers breastfeed longer and longer compared to women alone $[9,11]$. The single mothers and those who are unmarried, but in couples, breastfeed on a short period than the married mothers. The distinction between the married and the unmarried mothers but in couples has not been studied until now. Some studies show a link between the quality of the marital relationship of parents and the support of breastfeeding father. Moreover, it is possible that the marital status of the mother is correlated with other variables related to the duration of the breastfeeding. In this work, we have obtained a positive correlation between the level of the mother and the father education, father and the duration of the exclusive breastfeeding $(\mathrm{OR}=2.12 ; \mathrm{p}<0.001)$. Regarding the educational level, the adjusted odds ratio shows that women who have a higher level of education at the University or with a High School Diploma or with a Post-graduate level, breastfeed more often than women who have left the school at the collegial level [12]. Al Sahab in Canada has shown rather than having a higher level of education is a factor positively associated with the practice of an exclusive breastfeeding [13]. It is easy to understand this by the fact that mothers who have high levels of education have better knowledge of the benefits of breast milk.

The fact that the criterion "financial hardship" is also significant (OR: $2.895 \%$ CI $(1.2,6.3)$ ) can then surprise but it reflects the complexity of the women's profiles in the maintaining of a long-term breastfeeding. In contrast for the women with a favorable job situation, the limitation of the breastfeeding result from the organizational constraints required by their activities; for other women in less favorable situation, the breastfeeding constitute a solution more economic that the artificial milks. It is the same, without any doubt for the absence of professional activity that appears significantly in favor of breastfeeding for more than 12 weeks (OR: $2.095 \%$ CI $(1.4,2.8)$. In this study, we obtained a positive correlation between the occupational status of parents and the duration of exclusive breastfeeding $(\mathrm{OR}=1.74 ; \mathrm{p}<0.001)$. The professional environment plays an important role. The non-breastfeeding mothers justify their choice by the importance given to their work; the unemployed women (at home) or unemployed were less likely to breastfeed. The breastfeeding was not dependent on household income while the milk substitutes are expensive. It seems that the choice of the feeding method is related more to the social and cultural factors rather than the economic factors [14]. In this work, we have got a positive correlation between the socio-economic status and the parental socio-economic status (OR = $1.9 ; \mathrm{p}<0.001)$. The socio-economic status is also positively related to the breastfeeding; the women belonging to higher income scales would be more likely to initiate and continue the breastfeeding $[15,16]$.The maternal smoking is also a factor often cited [17] and the study confirms that the absence of smoking is in favor of the maintaining of the exclusive breastfeeding (OR: 3.9 95\% (1.2, 2.8 )) [18] or, at the opposite, that the smoking is registered against him. One know the difficulties of the smoking cessation are and it is very possible that the effort made by the women during the pregnancy and the lactation decrease with the time under the desire to of smoking again. This negative aspect of smoking, already described by many authors, is to be compared with that of Scott [15] which makes the synthesis and shows in his study an Odds Ratio of 1.35 for a smoking in favor of the early cessation of the breastfeeding. Clearly, full information of the dangers of smoking is necessary, not only during but also after pregnancy.The average duration of exclusive breastfeeding was $13.3 \pm 7.7$ weeks and less than a quarter of the children were breastfed exclusively breastfeeding during more than 6 months. That breastfeeding duration is superior to that of the 10 weeks revealed in the study of Branger [19] which covered all exclusive or mixed maternal feedings, which may suggest the existence of an increase, but one of the difficulties of the comparisons with international studies available, is that they are rarely focused on the duration of exclusive breastfeeding but more on that of the mixed breastfeeding. We however notes note that the observed rate of the exclusive breastfeeding in the study at 4 months is lower than that observed in the study of Taveras in the USA [13], where it is of 53\% and relatively close to that observed in Scott's study in Australia where it is of $28 \%$ [14]. In the study, the fathers had an influential role in the decision of women to breastfeed $[9,22]$ and that their support was crucial to the success of breastfeeding [3]. In Scott et al. [14] conducted in Australia, 59\% of women who perceived that their partner was more favorable to the breastfeeding, maintained the breastfeeding up to six months and 53\% of them had exclusively breastfed their child up to three months, against 30 and 26\%, respectively, of the women who perceived that their partner was more favorable to the bottle or ambivalent about the type of infant feeding. The mothers who breastfeed more than nine months their children have better relationships and express a greater satisfaction about the emotional support received from their spouse and their own mother, that the mothers who rapidly wean their child [15]. The father is a key actor in the supporting of the breastfeeding woman. It has been shown that its perception or his breastfeeding preferences are not without effect on the duration of breastfeeding $[16,21]$. Thus, the Miramichi study has showed that a negative view of the breastfeeding by the spouse lead to a shorter duration of breastfeeding [22]. Whereas the socio-economic characteristics of the father were rarely taken into account, the study of Miramichi has highlighted the 
associations between the duration of breastfeeding and many characteristics of the father (age, professional status, level of studies, socio-professional category).The breastfeeding is the reference for the feeding of infants during the first months of life. Health Canada in agreement with this Health Canada [4] promotes the breastfeeding as the best method of feeding infants, because it provides the best nutritional, immunological and emotional advantages for the growth and the development of child. It is recommended an exclusive breastfeeding during the first six months for term infants and healthy. These recommendations clearly aim to improve the health and the well-being of children and their mothers. It is estimated that the impact of breastfeeding is related to the composition of human milk, which brings many substances that are absent from commercial formula. However, the benefits of the breastfeeding are enough important to justify the efforts devoted to its promotion. Breastfeed exclusively until six months is a heavy burden for mothers, because many of them have a professional activity. For the improvement of health in New Brunswick, significant positive changes in health could be achieved if the breastfeeding become the norm for infant feeding.

Breastfeeding is the ideal way to providing the nutrients to infants. It provides all the calories and the nutrients that the child needs during the first months of life, and continue to cover half or more of nutritional needs during the second half of life, and up to one third of the nutritional requirements during the second year $[23,24]$. It has been suggested that children breastfed have concentrations of IGF-1 and insulin lower than nonbreastfed children. Furthermore, the concentrations of IGF-1 and insulin are negatively correlated to the duration of breastfeeding. These two hormones play an important role in the adipogenesis and in the accumulation of weight gain Hoppe, $[17,27]$, contributing to promote the sensory and cognitive development, and to protecting the infant against infectious and chronic diseases. Exclusive breastfeeding reduces the infant mortality related to common childhood illnesses such as diarrhea or pneumonia, and speeds healing in the case of illness. With few exceptions, $[18,28]$ the term infants and in healthy, need only the breast milk and the vitamin D supplements [19,29] to meet all their nutritional needs until the age of six months. The benefits of breastfeeding for the health of child and mothers were the subject of many studies. The benefits of breastfeeding are related to the duration and to its exclusivity. Indeed, the beneficial effects of breastfeeding on the health of the mother (and on that of the child) are related to its duration and its exclusivity: more the duration of breastfeeding is long (in months), and more it is exclusive (breast-fed infant only), more its beneficial effects are important. This explains why we so strongly recommend the exclusive breastfeeding during the first 6 months of life [30]. The breastfeeding is nutritionally important. In addition to providing immunological protection, it contributes to the growth and to the development of infants and young children.

Table1: Mode of milky feeding versus time

\begin{tabular}{|l|l|l|}
\hline & $0-6$ months & $6-12$ months \\
\hline Breastfeeding alone & 31,6 & 17,4 \\
\hline Breastfeeding and infant formula & 35,1 & 18,5 \\
\hline Infant formula & 33,3 & 64,1 \\
\hline
\end{tabular}

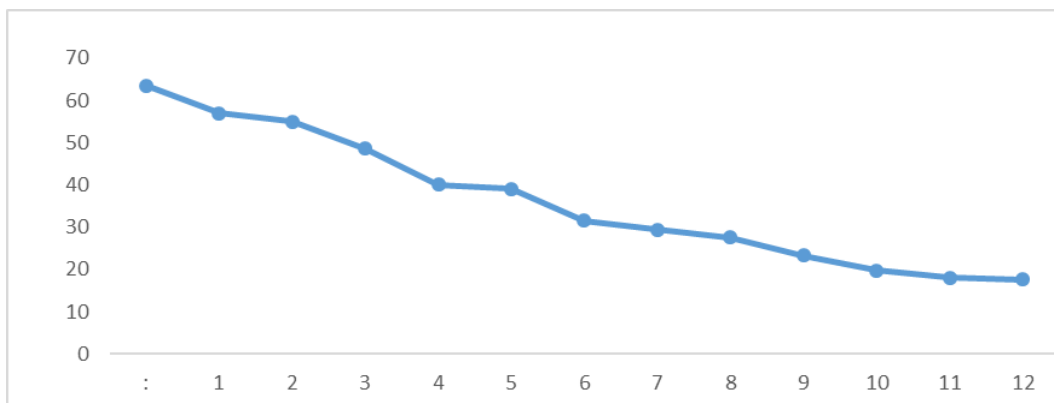

Figure 1: Proportion of mothers practicing exclusive breastfeeding versus the child's age

Table 2: Factors associated with cessation of breastfeeding according to the socio-demographic characteristics of mothers of young children aged from 0 to 6 months, in Miramichi: final model

\begin{tabular}{|l|l|l|l|}
\hline Characteristic & ORa & IC 95\% & P \\
\hline Maternal age & & & \\
$18-24$ & 1 & $--10,--$ & \\
$25-29$ & 0,97 & $(0,50-0,75)$ & 0,001 \\
$30-34$ & 1,2 & $(0,69-1,85)$ & 0,001 \\
$\geq 35$ & 1,8 & $(1,59-2,85)$ & 0,001 \\
\hline Marital status & & & \\
Married & 2,97 & $(0,93-3,15)$ & 0,001 \\
No married & 1 & -- & \\
\hline
\end{tabular}




\begin{tabular}{|c|c|c|c|}
\hline $\begin{array}{l}\text { Higest level of education completed } \\
\text { Community college } \\
\text { High School Diploma } \\
\text { University } \\
\text { Post-graduate }\end{array}$ & $\begin{array}{l}1 \\
1,62 \\
1,96 \\
2,12\end{array}$ & $\begin{array}{l}--- \\
(0,95-1,85) \\
(1,50-2,75) \\
(1,95-4,09)\end{array}$ & $\begin{array}{l}0,001 \\
0,001 \\
0,001\end{array}$ \\
\hline $\begin{array}{l}\text { Working Status } \\
\text { Working Full Time } \\
\text { Working part-Time } \\
\text { Not working }\end{array}$ & $\begin{array}{l}1,74 \\
1,63 \\
1\end{array}$ & $\begin{array}{l}(0,15-2,55) \\
(0,50-1,75) \\
---\end{array}$ & $\begin{array}{l}0,001 \\
0,001\end{array}$ \\
\hline $\begin{array}{l}\text { Total Household Income } \\
\text { Less than } \$ 20,000 \\
\$ 20,000-\$ 50,000 \\
\$ 50,000-\$ 100,000 \\
\geq \$ 100000\end{array}$ & $\begin{array}{l}1 \\
1,54 \\
1,63 \\
1,9\end{array}$ & $\begin{array}{l}(0,15-0,55) \\
(0,50-0,75) \\
(0,90-2,85)\end{array}$ & $\begin{array}{l}0,001 \\
0,001 \\
0,001\end{array}$ \\
\hline 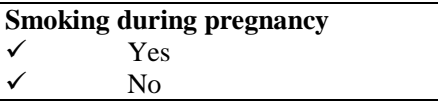 & $\begin{array}{l}3,9 \\
1\end{array}$ & $\begin{array}{l}(1,5-8,1) \\
----\end{array}$ & 0,001 \\
\hline $\begin{array}{ll}\text { Type of breastfeeding } \\
- & \text { Exclusive } \\
- & \text { Non exclusive } \\
\end{array}$ & $\begin{array}{l}3,1 \\
1\end{array}$ & $\begin{array}{l}(0,15-0,55) \\
-----\end{array}$ & 0,001 \\
\hline $\begin{array}{l}\text { Duration of breastfeeding } \\
\text { - Before } 6 \text { months } \\
\text { - After } 6 \text { months }\end{array}$ & $\begin{array}{l}1 \\
2,1\end{array}$ & $\begin{array}{l}------- \\
(0,90-2,85)\end{array}$ & 0,001 \\
\hline
\end{tabular}

\section{CONCLUSION}

This study has permitted to highlight the rate, the duration and the factors influencing the exclusive breastfeeding in the Miramichi region. The exclusive breastfeeding rate among children from 0 to 42 months increases strongly in Miramichi and the consequences of infant obesity that can persist during all the life, requires more aggressive and rapid interventions for this group of age. Furthermore, this study allowed us to identify seven factors associated with the cessation of the exclusive breastfeeding: the maternal age, the marital status, the level of education, the socio professional category, the salary level, the smoking, the type and duration of exclusive breastfeeding.

\section{REFERENCES}

[1] World Health Organization (WHO). The optimal duration of exclusive breastfeeding: Report of an expert consultation. Geneva, Switzerland: Department of nutrition for health and development and department of child and adolescent health and development; 2001.

[2] Turck D. Plan d'action: allaitement maternel. Propositions d'actions pour la promotion de l'allaitement maternel. Paris: Ministère de la Santé et des Sports; 2010. 40 p. http://www. sante.gouv.fr/IMG/pdf/Rapport_Plan_daction_allaitement_Pr_D_Turck.pdf

[3] Kramer M, Kakuma R. Optimal duration of exclusive breastfeeding (Review) 2007.

[4] Organisation mondiale de la santé. Stratégie mondiale pour l'alimentation du nourrisson et du jeune enfant. Durée optimale de l'alimentation au sein exclusive. Genève: OMS; 2001. 5 p. http://apps.who.int/gb/archive/pdf_files/whA54/fa54id4.pdf

[5] Fairbank L, O'Meara S, Renfrew MJ, Woolridge M, Sowden AJ, Lister-Sharp D. A systematic review to evaluate the effectiveness of interventions to promote the initiation of breastfeeding. Health Technol Assess. 4(25), 2000, 1-171. http://www.journalslibrary.nihr.ac.uk/_data/assets/pdf_file/0003/64947/FullReport-hta4250.pdf

[6] Ministère de la Santé et du Mieux-être du Nouveau-Brunswick. Base de données automatisée du SPSC de la Santé publique, 20042005 .

[7] Gouvernement du Nouveau-Brunswick, juin 2004. Un avenir en santé : objectifs et stratégies (amélioration de la santé de la population néo-brunswickoise; système de soins de santé viable pour les contribuables).

[8] Taveras EM, Li R, Grummer-Strawn L, Richardson M, Marshall R, Rêgo VH, et al. Opinions and practices of clinicians associated with continuation of exclusive breastfeeding. Pediatrics, 113, 2004, 283-90.

[9] Scott JA, Binns CW, Oddy WH, Graham KI. Predictors of breastfeeding duration: evidence from a cohort study. Pediatrics 117, 2006, 646-55

[10] Statistique Canada, 2015. Enquête sur la santé dans les collectivités canadiennes

[11] Labbok M, Krasovec K. Toward consistency in breastfeeding definitions. Stud Fam Plann 21(4), 1990, 226-30.

[12] World Health Organization. Données scientifiques relatives aux dix conditions pour le succès de l'allaitement. Geneva: WHO; 1999.

[13] Al-Sahab B, Lanes A, Feldman M, Tamim H. Prevalence and predictors of 6-month exclusive breastfeeding among Canadian women: a national survey. BMC Pediatr. 2010, 10-20

[14] Blyth RJ, Creedy DK, Dennis CL, Moyle W, Pratt J, De Vries SM, et al. Breastfeeding duration in an Australian population: the influence of modifiable antenatal factors. J Hum Lact 20, 2004, 30-8.

[15] Scott JA, Binns CW, Oddy WH, Graham KI. Predictors of breastfeeding duration: evidence from a cohort study. Pediatrics, 117, 2006, 646-55.

[16] Peters E, Wehkamp KH, Felberbaum RE, Kruger D, Linder R. Breastfeeding duration is determined by only a few factors. Eur J Public Health 16, 2006, 162-7.

[17] Dennis CL. Breastfeeding initiation and duration: A 1990_2000 literature review. J Obstet Gynecol Neonatal Nurs 3, 2002,: 1232.

[18] DiGirolamo A, Thompson N, Martorell R, Fein S, GrummerStrawn L. Intention or experience? Predictors of continued breastfeeding. Health Educ Behav 32, 2005, 208-26.

[19] Kohlhuber M, Rebhan B, Schwegler U, Koletzko B, Fromme H. Breastfeeding rates and duration in Germany: A Bavarian cohort study. Br J Nutr 99, 2008, 1127-32.

[20] Righard L, Alade MO. Sucking technique and its effect on success of breastfeeding. Birth 19, 1992, 185 -9. 
[21] Liu J, Rosenberg KD, Sandoval AP. Breastfeeding duration and perinatal cigarette smoking in a population-based cohort. Am J Public Health 96, 2006, 309-14.

[22] Blyth RJ, Creedy DK, Dennis CL, Moyle W, Pratt J, De Vries SM, et al. Breastfeeding duration in an Australian population: the influence of modifiable antenatal factors. J Hum Lact 20, 2004, 30-8.

[23] Kronborg H, Vaeth M. The influence of psychosocial factors on the duration of breastfeeding. Scand J Public Health 32, 2004, $210-6$.

[24] Branger B, Cebron M, Picherot G. Facteurs influençant la durée de l'allaitement maternel chez 150 femmes. Arch Pediatr, 5, 1998, $489-96$.

[25] Nielsen GA, Thomsen BL, Michaelsen KF. Influence of breastfeeding and complementary food on growth between 5 and 10 months. Acta Paediatr 87, 1998, 911-7.

[26] Rolland-Cachera MF, Deheeger M, Akrout M, Bellisle F. Influence of macronutrients on adiposity development: a follow up study of nutrition and growth from 10 months to 8 years of age. International journal of obesity and related metabolic disorders : Journal of the International Association for the Study of Obesity 19, 1995, 573-8.

[27] Hoppe C, Rovenna Udam T, Lauritzen L, Mølgaard C, Juul A, Fleischer Michaelsen K. Animal protein intake, serum insulin-like growth factor I, and growth in healthy 2.5-yold Danish children. The American Journal of Clinical Nutrition 80, $2004,447-52$.

[28] Rolland-Cachera MF, Deheeger M, Maillot M, Bellisle F. Early adiposity rebound: causes and consequences for obesity in children and adults. Int J Obes 30, 2006, 11- 7.

[29] Gunther AL, Buyken AE, Kroke A. Protein intake during the period of complementary feeding and early childhood and the association with body mass index and percentage body fat at 7 y of age. Am J Clin Nutr 85, 2007, 1626-33.

[30] Feldman, P. Evidence-based Benefits of Breastfeeding for the Breastfeeding Committee for Canada: 2005. An Annotated. 